\title{
ASSESSMENT OF ANTI-POACHING EFFORT IN RUAHA NATIONAL PARK, TANZANIA
}

\author{
CL Nahonyo \\ Department of Zoology and Wildlife Conservation, University of Dar es Salaam, \\ P. O. Box 35064, Dar es Salaam, Tanzania. \\ nahonyo@uccmail.co.tz
}

\begin{abstract}
Anti-poaching effort in Ruaha National Park for the period between January 1996 to June 1999 was evaluated in terms of strength, frequency and duration of patrols, area covered and success of patrols. It was found that the park spent 72.4 US\$ km year on law enforcement. There were 72 rangers each required to patrol on the average $143 \mathrm{~km}^{2}$. A total of 1,255 patrols were conducted; patrols ranged from 14 to 43 trips per month and each lasted between 1 to 25 days and most were foot and vehicle patrols. Patrol units had 2 to 11 rangers while the average patrol effort ranged from 36 ranger-days $100 \mathrm{~km}^{-2}$ year ${ }^{-1}$ to 120 ranger-days $100 \mathrm{~km}^{-2}$ year . The success of sighting poaching signs varied from 4.3 signs 100 ranger-days ${ }^{-1}$ to 10.5 signs 100 ranger-days ${ }^{-1}$. Patrol units on foot were more likely to sight poachers than those on vehicles. Armed patrols were more likely to encounter poaching gangs during the dry than wet season possibly because visibility was better in the dry season. About $90 \%$ to $100 \%$ rangers were armed during patrols. Over $60 \%$ of encountered poachers were arrested. Increasing the number of armed patrol units is likely to increase success in sighting and arresting poachers through improving patrol efficiency. However, this should be coupled with increased funding; patrol vehicles, ranger force and improved road system.
\end{abstract}

\section{INTRODUCTION}

Establishment of protected areas (PAs) and institution of various conservation laws, has systematically, through time, alienated the indigenous people from the right to utilise and manage natural resources. Most indigenous people, however, tend to continue utilising these resources illegally partly because they cannot afford to buy licenses involved in securing legal utilization. They go for resources in the PAs due to their cultural values, economic value, depletion of resources in open areas, and lack of alternative space for expansion. The types of resources exploited, levels and nature of utilisation, are highly variable and depend on the resources available, the indigenous people and sometimes outside pressure where businessmen inject money to local people so enticing them to exploit the resources illegally. Illegal hunting of animals for trophy and meat, is usually a major problem experienced in PAs, and is more or less universal in conservation areas of Africa north of the Limpopo (Bell 1984a).

Barnes and Kapela (1991) reported a decline of over $60 \%$ of elephants in Ruaha National Park (NP) due to illegal hunting in the 1980s. Likewise, Eltringham and Malpas (1980) reported a decline of $26 \%$ and $17 \%$ respectively, in elephant populations between 1973 and 1976 in two protected areas of Rwenzori and Kabalega in Uganda. The Tanzania Wildlife Conservation Monitoring (Anon 1990, 1993, 1996) aerial counts in the Greater Ruaha Ecosystem, reported a high elephant-carcass ratio sightings during the $1980 \mathrm{~s}$, indicating a high rate of elephant hunting. Also, LeaderWilliams et al (1990) reported a decline of 0.63 and -0.12 for rhinos and elephants respectively, in Luangwa Valley, Zambia, due to poaching in the 1980 s.

In order to protect the natural resources inside PAs, laws and regulations have been 
instituted and enforced by law enforcement organs. These organs have in many cases become antagonistic with the indigenous people due to differences in the way the two sides perceive the natural resources (Newmark et al. 1993). Through decades, the law enforcement organs have in many cases not been very effective in saving the species from decline, particularly elephants and rhinos (Leader-Williams et al. 1990).

Ruaha NP was gazetted in 1964 and is the second largest in the country after Serengeti National Park. It covers $10,200 \mathrm{~km}^{2}$ and harbours a high concentration of large mammals. Most of the inhabitants in villages surrounding the park were resettled there after gazetting the NP. The present study evaluated efforts invested by the park in protecting wildlife resources. Also during this study an evaluation of the success of the village scouts was conducted in an area under the auspices of the Matumizi Bora ya Malihai Idodi na Pawaga (MBOMIPA) Community-based Conservation (CBC) Project which collaborates with the national park in patrolling Wildlife Management Areas (WMA) adjacent to the Ruaha NP. The study also briefly discusses the contribution in law enforcement of game scouts under the local government authorities in the area.

\section{MATERIALS AND METHODS}

Ruaha National Park is located between E $033^{\circ} 49^{\prime}$ and $\mathrm{E} 035^{\circ} 24^{\prime}$, and $\mathrm{S} 06^{\circ} 52^{\prime}$ and $\mathrm{S} 07^{\circ} 57^{\prime}$ in south-central Tanzania and forms part of the Greater Ruaha Ecosystem with altitude ranging between $750-1830 \mathrm{~m}$ above sea level. The terrain is undulating landscape dominated by a mosaic of vegetation types ranging from open grassland to submontane forest. Rainfall is unimodal and averages $650 \mathrm{~mm}$ per annum. Mean annual temperature is $24^{\circ} \mathrm{C}$. The park is divided into four anti-poaching zones (Fig. 1) all of which were sampled in the present study.

Effective strength of the ranger force in the park was assessed in relation to the total area to be patrolled, number of arms and vehicles and budget allocated to law enforcement.

The number of patrols per unit time and space was assessed to determine how frequent patrols were conducted in different parts of the park. The number of days spent on patrol for each particular excursion was recorded. These were then correlated to the number of poachers arrested to determine whether the duration of a patrol was related to the success of an operation.

Areas covered during patrols were estimated to determine the effectiveness of the patrols. The process involved marking patrolled areas on topographic sheets $(1: 50,000)$, which were later used to estimate the area covered during patrol by joining the points on the map to form polygons.

The success of patrol operations was taken to be the number of poachers arrested per unit effort, considering the time and area covered on patrol. Information on field patrols were obtained from relevant offices in Ruaha National Park, patrol success was compared between the different zones in the park (Fig. 1). Comparative data used in discussion was obtained from MBOMIPA office at Iringa, Rungwa /Kisigo/ Muhesi GRs, Anti poaching office in Manyoni and district natural resources offices. 


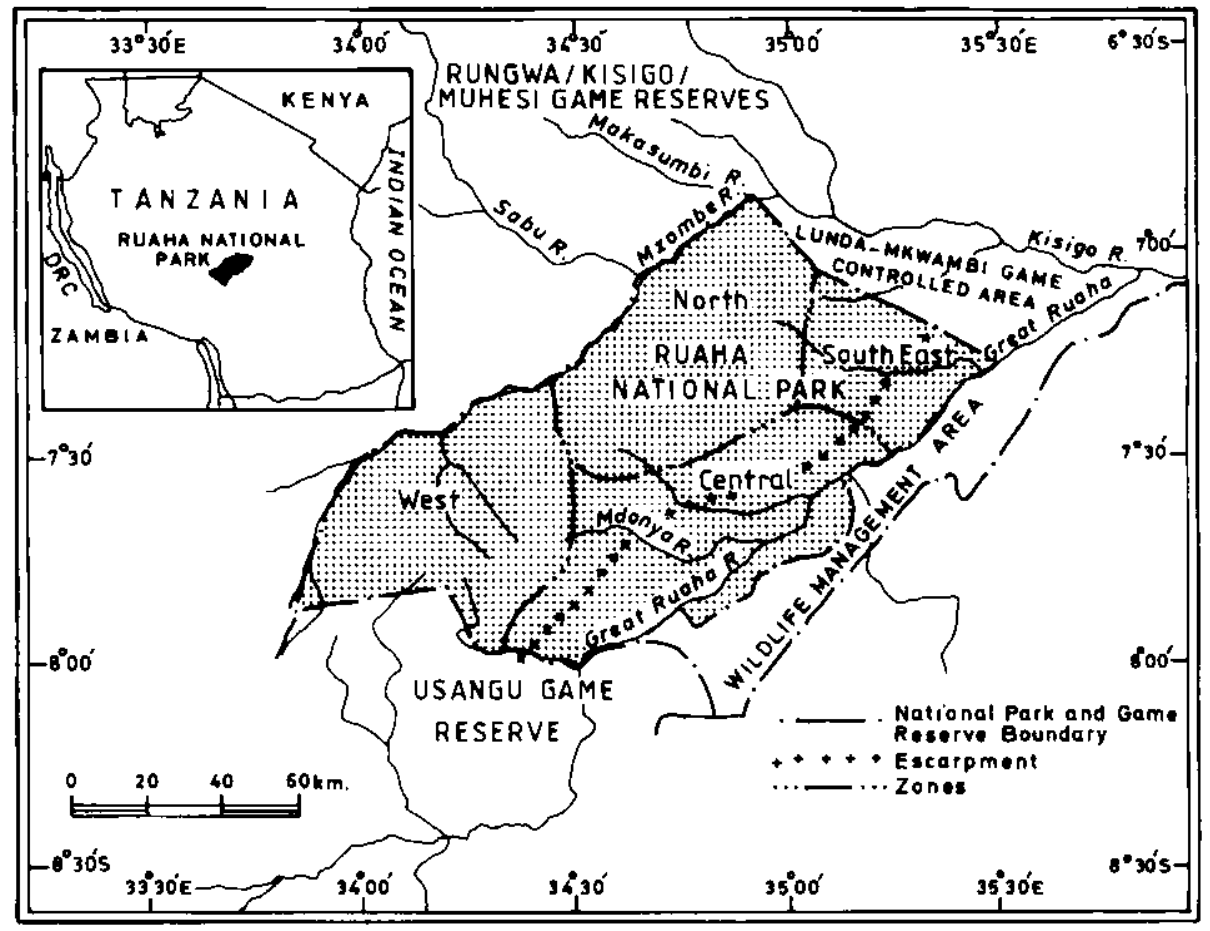

Figure 1: Ruaha National Park showing anti-poaching patrol zones, and position of the park in Tanzania (inset)

Poaching signs were weighted by dividing the number of signs observed by effective patrol effort (ranger-days in each month), to get the number of poaching signs/day rangers/month. Effective patrol days were taken as the full days (over 8 hours of patrol time) when rangers conducted patrols on foot. For joint vehicle and foot patrols, days when rangers used vehicles were excluded in computing effective patrol effort. Also, the mean success in arresting poachers, i.e. poachers arrested as a proportion of total number of poachers sighted in a gang was computed for each month. The two variables were used as test variables in a general linear model (GLM) to determine the factors influencing them (Zar 1999). Season, area, patrol effort (day rangers), possession of firearms by patrol units, type of offence committed, and gang size, were used as categorical variables. The probability of discovering a poacher gang during patrol (presence/absence) was tested using Multinomial Stepwise Logistic Regression (MSLR). Season, area, gang size, offence committed, patrol effort and whether the patrol units were armed or not, were independent variables. Differences between proportions were tested using a $\mathrm{d}$ test (Parker 1973).

\section{RESULTS}

Strength of the anti-poaching force

The ranger force of Ruaha NP is primarily responsible for patrolling areas inside the park. Game scouts under local government authorities are extremely few and are mostly involved in controlling problem animals (e.g. elephant, hippo, buffalo, crocodile), rather than patrolling their area outside PAs. However, the Game Scouts under local authority have been a good source of 
Nahonyo - Assesment of anti-poaching effort in Ruaha ...

intelligence information for parks and antipoaching units regarding illegal activities happening in their area. With ranger force of 72 strong and an area of $10,200 \mathrm{~km}^{2}$ each ranger in Ruaha is supposed to patrol on the average $142 \mathrm{~km}^{2}$. This is the recommended ratio of 50 $\mathrm{km}^{2} / \mathrm{scout}$ (Bell 1984, Anon 1998). Ruaha
$\mathrm{NP}$ is under funded spending about 72.4 US\$ $\mathrm{km}^{-2}$ year ${ }^{-1}$. The adjacent Rungwa/Kisigo/Muhesi GRs spend only 2.5 US\$ $\mathrm{km}^{-2}$ year ${ }^{-1}$ for all expenses including development and recurrent expenditure. It implies that in the latter case the money that goes directly into law enforcement is thus, much less (Table 1).

Table 1: Strength of anti-poaching forces between Ruaha National Park with areas surrounding the park within the Greater Ruaha Ecosystem, Tanzania in 1999

\begin{tabular}{lccccc}
\hline \multicolumn{1}{c}{ Location } & Area $\left.\mathbf{( k m}^{2}\right)$ & Scouts & Firearms & Vehicles & Area $\left(\mathbf{K m}^{2}\right)$ scout $^{-1}$ \\
\hline Ruaha NP & 10,281 & 72 & 68 & 7 & 143 \\
Rungwa/Kisigo/Muhesi GRs & 13,162 & 38 & 25 & 7 & 346 \\
Mbarali District & 16,000 & 6 & 8 & 0 & 2,667 \\
Dodoma District & 14,004 & 4 & 4 & 1 & 3,501 \\
Iringa District & 18,620 & 8 & 6 & 1 & 2,328 \\
Iringa Anti-poaching zone & 121,356 & 25 & 60 & 3 & 4,854 \\
Village scouts (MBOMIPA & 3,000 & 40 & - & - & 76 \\
Project, CBC Programme) & & & & & \\
\hline
\end{tabular}

\section{Frequency and duration of patrols}

Between January 1996 and June 1999 1,255 patrol trips were conducted in Ruaha NP. The frequency of patrols ranged from 14 to 43 trips per month for the whole park, lasting on the average 3 days (range $1-25$ days). Day patrol trips constituted $45.2 \%$ of all patrols. About $50 \%$ of the patrol trips lasted between 2 - 10 days, and only $1.9 \%$ lasted over 10 days. Over $50 \%$ of all patrols were conducted on foot (from start to end), whereas $46.2 \%$ combined vehicle and foot patrols. At least 6 aircraft patrols $(0.1 \%)$ were conducted to provide ground forces with information about the location of poachers and/or poaching activities.

\section{Area covered on patrol and patrol effort}

Due to insufficient number of rangers, patrol groups were obliged to patrol large areas. Patrol effort ranged from 1.3 days ranger ${ }^{-1}$ month $^{-1}$ to 13.3 days ranger ${ }^{-1}$ month $^{-1}$. Patrol units averaged $2-11$ rangers $($ mean $=6)$ for foot patrols and $2-19$ rangers $($ mean $=7)$ for vehicle patrol units. Most of the time, $90 \%$ to $100 \%$ of all rangers on patrol were armed. Average patrol effort per unit area ranged from 36 ranger-days $100 \mathrm{~km}^{-2}$ year to 120 ranger-days $100 \mathrm{~km}^{-2}$ year ${ }^{-1}$. Park authorities also depended on intelligence reports from their rangers, park agents, village scouts and local government scouts to determine places to conduct intensive patrols. The central and southeastern parts of Ruaha National Park were relatively the most frequently patrolled areas at 10 rangerdays $100 \mathrm{~km}^{-2} \mathrm{month}^{-1}$, while the northern parts were patrolled at 4 ranger-days $100 \mathrm{~km}$ 2 month $^{-1}$. The western parts were the least frequently patrolled at 3 ranger-days $100 \mathrm{~km}$ ${ }^{2}$ month $^{-1}$.

Success of patrol units in sighting poaching signs and poachers

Poaching signs included sighting animal carcasses, poaching parties, hearing gunshots, footprints, camps, fire and/or smoke and sawing pits (Table 2). The rate of sighting ranged from 4.3 signs 100 rangerdays $^{-1}$ to 10.5 signs 100 ranger-days ${ }^{-1}$. The spatial distribution of signs varied from 1.8 to 2.7 signs $100 \mathrm{~km}^{-2}$ between different years. The probability of sighting a sign was dependent on the mode of patrol $\left(\mathrm{F}_{3,1067}=\right.$ 9.127, P $<0.001$, GLM). Patrol units on foot, were more likely to sight poaching 
signs, than those on vehicle patrol. Aircraft patrols were quite efficient in spotting poaching parties, camps and fire and/or smoke from the air. The author participated in some patrol trips and observed that rangers spent at least $8-10$ hours on foot patrol (on each day they went out). Rangers usually moved in an extended line, with individuals walking 10 to $50 \mathrm{~m}$ apart, depending on visibility, vegetation type, terrain and security situation. This mode of patrol increased the effective patrol area. In areas with thick vegetation or incidences of danger, rangers moved in a single file.
Visibility was variable, ranging from only 2 $\mathrm{m}$ in areas with thick vegetation to $50-100$ $\mathrm{m}$ in sparsely vegetated areas. Frequently, rangers used binoculars to improve their observatory efficiency. Visibility was poor in the wet season due to thick vegetation, which probably decreased the ability to sight poachers. Patrol units were significantly more successful $(\mathrm{d}=6.317, \mathrm{P}<0.001)$ in sighting poachers during the dry season field trips $60.2 \%(\mathrm{n}=538)$ than during the wet season field trips $42.9 \%(\mathrm{n}=717)$.

Table 2: Poaching signs sighted by patrol units in Ruaha NP, Tanzania between 1995 and 1999

\begin{tabular}{|c|c|c|c|c|c|}
\hline \multirow{2}{*}{ Poaching signs } & \multicolumn{5}{|c|}{ Frequency } \\
\hline & 1995 & 1996 & 1997 & 1998 & To June 1999 \\
\hline Patrol effort: day-scouts $100 \mathrm{~km}^{-2} \mathrm{month}^{-1}$ & 8.0 & 4.8 & 3.7 & 3.5 & 4.2 \\
\hline Poacher gangs & 20 & 23 & 18 & 30 & 21 \\
\hline Footprints & 32 & 35 & 27 & 41 & 21 \\
\hline Fishing & 8 & 8 & 3 & 6 & 0 \\
\hline Poacher camps & 16 & 4 & 11 & 16 & 10 \\
\hline Gun shots & 5 & 9 & 5 & 8 & 6 \\
\hline Meat driers & 4 & 5 & 5 & 5 & 4 \\
\hline Hunting & 15 & 16 & 5 & 30 & 6 \\
\hline Honey gathering & 4 & 5 & 7 & 3 & 14 \\
\hline Smoke & 1 & 1 & 5 & 2 & 3 \\
\hline Timber harvesting & 1 & 3 & 3 & 1 & 0 \\
\hline Farming encroachment & 0 & 2 & 0 & 1 & 0 \\
\hline Grazing in the park & 0 & 3 & 5 & 5 & 1 \\
\hline Bicycle tyre tracks & 0 & 4 & 0 & 0 & 1 \\
\hline Vehicle tyre tracks & 0 & 0 & 0 & 1 & 0 \\
\hline Snares and traps & 0 & 1 & 1 & 0 & 0 \\
\hline Bushfire & 0 & 0 & 0 & 1 & 0 \\
\hline Tree cutting & 0 & 0 & 0 & 0 & 1 \\
\hline Elephant carcasses & 21 & 37 & 5 & 12 & 1 \\
\hline Other animals carcasses & 7 & 29 & 22 & 38 & 11 \\
\hline Total & 134 & 185 & 122 & 200 & 100 \\
\hline
\end{tabular}


Probability of discovering poaching gangs by patrol units

Armed patrols in the park were more likely to encounter poaching gangs during the dry season $\left(\mathrm{R}^{2}=0.067, \mathrm{P}<0.037\right.$, Multiple
Stage Linear Regression). The regression model correctly predicted the estimates by $57.0 \%$. The probability of sighting poachers at any given time in the two seasons could be computed using the logistic regression equations:

$$
\begin{aligned}
& \text { Dry season } \\
& \text { Probability }=\frac{\underline{\mathbf{e}}^{\left(0.08266+0.01911^{*} \text { Day-arms }\right)}}{\mathbf{1}+\mathbf{e}^{\left(0.08266+0.01911^{*} \text { Day-arms }\right)}} \\
& \text { Wet season: } \\
& \text { Probability }=\underline{\mathbf{e}} \frac{\mathbf{e}^{\left(0.08266+0.01911^{*} \text { Day-arms }\right)+(-0.728)}}{\mathbf{1}+\mathbf{e}^{\left(0.08266+0.01911^{*} \text { Day-arms }\right)+(-0.728)}}
\end{aligned}
$$

Where:

$\mathbf{e}=2.71828,0.08266=$ regression coefficient for day-arms (day-arms = product of days on patrol and number of firearms carried), $-0.728=$ regression coefficient for wet season. The regression coefficient for the dry season was redundant. Some probabilities for sighting poachers in dry and wet seasons have been calculated for 7 selected values (Table 3 ). At least $35.6 \%$ of all poaching parties arrested were armed with guns, and some poachers possessed the fatal poison arrows.

Table 3: Probabilities of sighting poachers for 7 selected values of day-arms in Ruaha NP, Tanzania between 1995 and 1999

\begin{tabular}{lcc}
\hline \multirow{2}{*}{ Day-arms } & \multicolumn{2}{c}{ Probability (P) } \\
\cline { 2 - 3 } & Dry season & Wet season \\
\hline 5 & 0.544 & 0.366 \\
10 & 0.568 & 0.388 \\
15 & 0.591 & 0.411 \\
20 & 0.614 & 0.434 \\
25 & 0.636 & 0.458 \\
30 & 0.658 & 0.481 \\
100 & 0.880 & 0.779 \\
\hline
\end{tabular}

\section{Success of patrol units in arresting poachers}

The success in arresting poachers once spotted varied from $0 \%$ when all poachers escaped to $100 \%$, when all those spotted were arrested. On $17.8 \%$ occasions, all sighted poachers managed to escape arrest, while on $28.2 \%$ occasions all were arrested. The average arrest success was $66.3 \%$ of all the poachers spotted. The success was a function of the patrol effort applied $\left(\mathrm{F}_{1}, 1058\right.$ $=7.722, \mathrm{P}<0.001, \mathrm{GLM})$. The more rangers and time spent on patrol, the more successful the patrol groups were able to arrest poachers.

The establishment of village game scouts through the MBOMIPA Project in the Lunda Mkwambi South WMA has provided some encouraging results in relation to law 
enforcement endeavors in the area. Between 1996 and 1999, the village scouts despite being ill equipped managed to arrest $43.3 \%$ of all poachers $(n=457)$ arrested in areas around Ruaha NP. The village scouts also provided useful intelligence information regarding illegal activities since they lived amongst the potential poachers in the villages (Table 4).

Table 4: Success of village scouts patrols under MBOMIPA Project CBC programme, around Ruaha NP in Tanzania, between 1996 and 1999 (Source: MBOMIPA Project)

\begin{tabular}{ll}
\hline \multicolumn{1}{c}{ Activity } & \multicolumn{1}{c}{ Success } \\
\hline Arresting poachers & 198 poachers arrested \\
Recovering guns used in poaching & 69 muzzle loaders, 1 shot gun recovered \\
Recovering elephant ivory & 3 tusks recovered \\
Recovering timber & 512 timber pieces recovered \\
Recovering other trophies & 1 leopard skin recovered \\
\hline
\end{tabular}

\section{DISCUSSION}

The field patrol force for Ruaha National Park is the recommended level of at most 50 $\mathrm{km}^{2}$ ranger $^{-1}$ (Bell 1984b, Anon 1998). The current size of the ranger force needs to be tripled in order to reach the recommended level. This will possibly ensure that most areas of the park are effectively patrolled. This is still important even in the current situation where community conservation is being promoted as temptations for poaching still remain for some elements in society. However, efforts to control illegal activities are also undermined by the lack of adequate funding and equipment. There are also logistical problems associated with patrolling in the park. Most of the roads are seasonal, so transporting rangers to distant and remote patrolling areas tend to be difficult during the wet seasons. The consequence is to have few areas being more frequently patrolled than others.

With the available number of rangers the frequency of patrols was probably adequate but this needs to be increased by increasing the number of rangers. Frequent patrols ensure continued vigilance in most areas so keeping poachers at bay. Also the proportion of day patrols needs to be reduced in replacement of longer trips for more effective operations.

The area covered by patrols was relatively small compared to the total area of the park. This is due to the low number of rangers and sometimes logistical problems. Efficient transport and good road system would have increased the total area covered. Transport is particularly important because the combined foot and vehicle patrols tended to cover larger areas and proved to be more effective in locating and arresting poachers.

The nature and intensity of illegal offences in the park like in other areas was complex and depended upon different factors such as the types of natural resources, and communities surrounding PAs. For example, elephant poaching for ivory was done by the local people, but the motivation came from beyond the borders of the ecosystem and country. There were many types of offenses happening inside the park and surrounding areas (Table 2) although most signs and offenses were related to hunting. Patrol parties were quite successful in locating these signs and poachers. However, there were no reports that illegal hunting seriously threatened other wildlife species, apart from elephants and rhinos in 
the park at least in the past. But timber tree species were reported to be seriously affected by illegal harvesting in the WMA and most were harvested below recommended diameter at breast height (L. Mwasumbi pers. Comm. 2005). The greater part of the sawn logs contained almost half of it as sapwood, which is valueless as a timber product. Harvesting is recommended when the oldgrowth miombo has reached a basal area of $7.0 \mathrm{~m}^{2} \mathrm{ha}^{-1}$ for dry miombo, and $22.0 \mathrm{~m}^{2} \mathrm{ha}^{-}$ ${ }^{1}$ for wet miombo, respectively (Boaler et al. 1966). Problems associated with farming and grazing inside PAs were not very serious at the moment, but were gradually growing, and bound to become key management issues in future. Expanding human populations due to immigration and natural increase were gradually reclaiming land towards the park.

The results of MSLR indicated that discovering poaching gangs depended on the rangers being armed and days of patrol. However, the magnitude of $\mathrm{R}^{2}$ suggests that there are other factors also influencing the chances of discovering poaching gangs. In addition, being armed, probably instilled some confidence on the rangers to pursue poachers, some of them armed with automatic rifles. Calculated probabilities from selected values of day-arms showed that increasing the number of armed rangers and days on patrol improved the chance of discovering poachers. As expected, the same values of day-arms provided less chances of sighting poachers during wet season compared to the dry season most likely due to poor visibility.

Within the limitations of resources, the antipoaching forces in the park were doing a commendable work; they arrested $66 \%$ of all sighted poachers. This suggests that increasing effective patrol effort is likely to improve arrests, but this should be expected to increase to a point where increasing effort will not increase arrests as all patrol units would then be arresting most of the poachers taking part on illegal activities. At this point, the number of arrests would gradually come to a level, and approach an asymptote. This would be the optimum effective patrol effort required, whereby increasing patrol effort would not raise the catch per unit effort and hence be unnecessary. Alternatively, by increasing effective patrol effort, there is also a possibility that poachers would be intimidated to participate in poaching, as such, the number of arrests might fall drastically as poachers become discouraged by strong patrol units. The third alternative is where the arrests would increase linearly, and then go into instantaneous fluctuations depending on a number of factors like season or instantaneous patrol efforts being applied. This is basically an intermediate of the two extreme cases.

Physical boundaries like highly flooded rivers (in the wet season) tend to block poachers from entering the park, but at the same time they may also obstruct patrol units from pursuing poachers on the opposite bank. During this time, there were reports of poachers attempting to cross (at night), using the only accessible route into the south-central area of the park, which was a guarded bridge at the park main entrance gate. Poachers often recruit young close family members, relatives, and friends to join in illegal activities. Most are likely to accept since they are made to believe that this is the only way to make a living. Efforts to discourage youths from engaging in poaching would help to control illegal activities in the long run since potential poachers would get fewer as the elderly ones retire due to old age.

\section{ACKNOWLEDGEMENTS}

I thank the World Wildlife Fund for nature (WWF-USA), The Wildlife Conservation Society (WCS-New York), Research Programme on Sustainable Use of Dryland Biodiversity (RPSUD), the Wildlife Division of Tanzania and University of Dar es Salaam for funding this research. Prof. Nigel Leader-Williams and Dr Bob Smith 
advised on data processing and Prof. Ingvar Backeus for reading the manuscript.

\section{RERERENCES}

Anonymous 1990 Survey report, Greater Ruaha, 1990. Tanzania Wildlife Conservation Monitoring (TWCM); Joint Project between Serengeti Wildlife Research Institute, the Wildlife Division, Tanzania National Parks, Ngorongoro Conservation Area Authority and Frankfurt Zoological Society

Anonymous 1993 Wildlife Census: Greater Ruaha Wet \& Dry Seasons 1993. Tanzania Wildlife Conservation Monitoring (TWCM); Joint Project between Serengeti Wildlife Research Institute, the Wildlife Division, Tanzania National Parks, Ngorongoro Conservation Area Authority and Frankfurt Zoological Society

Anonymous 1996 Greater Ruaha Ecosystem SRF 1996. Tanzania Wildlife Conservation Monitoring (TWCM); Joint Project between Serengeti Wildlife Research Institute, the Wildlife Division, Tanzania National Parks, Ngorongoro Conservation Area Authority and Frankfurt Zoological Society

Anonymous 1998 Ruaha National Park General Management Plan. Tanzania National Parks (TANAPA), Arusha, Tanzania

Barnes RFW and Kapela EB 1991 Changes in Ruaha elephant population caused by poaching. African Journal of Ecology 29(4): 289-294
Bell RHV 1984a Traditional use of wildlife resources in protected areas In: Conservation and Wildlife Management in Africa (Eds. R. H. V. Bell and E. McShane-Caluzi), pp. 297-315. USAID, Washington D. C.

Bell RHV 1984b Monitoring illegal activity and law enforcement in African conservation areas In: Conservation and Wildlife Management in Africa (Eds. R. H. V. Bell and E. McShane-Caluzi), pp. 317-351. USAID, Washington D. C.

Boaler SB and Sciwale KC 1966 The Ecology of a Miombo site, Lupa North Forest Reserve, Tanzania. Unpublished Report

Eltringham SK and Malpas RC 1980 The Decline in elephant numbers in Rwenzori and Kabalega National Parks, Uganda. African Journal of Ecology 18: 73-86

Leader- Williams N, Albon SD and Berry PS 1990 Illegal exploitation of rhinoceros and elephant populations: patterns of decline, law enforcement and patrol effort in Luangwa valley, Zambia. Journal of Applied Ecology 27(3): 10551087

Newmark WD, Leonard NL, Sariko HI and Gamassa DM 1993 Conservation Attitudes of Local People Living Adjacent to Five Protected Areas in Tanzania. Biological Conservation 63: 177-183

Parker RE 1973 Introductory Statistics for Biology: Studies in Biology No. 43. Edward Arnold Ltd. London

Zar JH 1999 Biostatistical Analysis $3^{\text {rd }}$ Edition, Prentice Hall Inc., New York 